\title{
Applicability of the Decision Matrix of North Eastern Atlantic, Mediterranean and connected seas Tsunami Warning System to the Italian tsunamis
}

\author{
S. Tinti ${ }^{1}$, L. Graziani ${ }^{2}$, B. Brizuela ${ }^{2}$, A. Maramai $^{2}$, and S. Gallazzi* \\ ${ }^{1}$ Dipartimento di Fisica, Settore di Geofisica, Università di Bologna, Bologna, Italy \\ ${ }^{2}$ Istituto Nazionale di Geofisica e Vulcanologia, Roma, Italy \\ * formerly at: Dipartimento di Fisica, Settore di Geofisica, Università di Bologna, Bologna, Italy \\ Correspondence to: L. Graziani (laura.graziani@ingv.it)
}

Received: 19 December 2011 - Revised: 14 February 2012 - Accepted: 15 February 2012 - Published: 30 March 2012

\begin{abstract}
After the 2004 Indian Ocean tsunami catastrophe, UNESCO through the IOC (Intergovernmental Oceanographic Commission) sponsored the establishment of Intergovernmental Coordination Groups (ICG) with the aim to devise and implement Tsunami Warning Systems (TWSs) in all the oceans exposed to tsunamis, in addition to the one already in operation in the Pacific (PTWS). In this context, since 2005, efforts have begun for the establishment of TWSs in the Indian Ocean (IOTWS), in the Caribbean area (CARIBE EWS) and in the North Eastern Atlantic, the Mediterranean and Connected Seas (NEAMTWS).
\end{abstract}

In this paper, we focus on a specific tool that was first introduced in the PTWS routine operations, i.e., the Decision Matrix (DM). This is an easy-to-use table establishing a link between the main parameters of an earthquake and the possible ensuing tsunami in order to make quick decision on the type of alert bulletins that a Tsunami Warning Center launches to its recipients. In the process of implementation of a regional TWS for the NEAM area, two distinct DMs were recently proposed by the ICG/NEAMTWS, one for the Atlantic and the other for the entire Mediterranean area.

This work applies the Mediterranean NEAMTWS DM to the earthquakes recorded in Italy and compares the action predicted by the DM vs. the action that should be appropriate in view of the observed tsunami characteristics with the aim to establish how good the performance of the Italian TWS will be when it uses the DM for future events. To this purpose, we make use of the parametric catalogue of the Italian earthquakes (CPTI04) compiled in 2004 and the most recent compilation of the Italian tsunami, based on the Italian Tsunami Catalogue of 2004 and the subsequent revisions. In order to better compare the TWS actions, we have identified four different kinds of action coding them from 0 to 3 according to the tsunami severity and have further considered three different distance ranges where these actions apply, that is local, regional and basin-wide, that refer to the distance of the message recipients from the tsunami source. The result of our analysis is that the actions prescribed by the DM are adequate only in $45 \%-55 \%$ of the cases, overestimations are about $37 \%$ and underestimations are the rest. As a whole, the predictive ability of the DM is not satisfactory, which implies that recipients have the difficult task in managing bulletins carrying a great deal of uncertainty and on the other hand also suggests that strategies to improve the DM or to go beyond the DM need to be found.

\section{Introduction}

The occurrence of the 2004 Indian Ocean tsunami increased public awareness that a tsunami can cause devastating effects even very far from its source. The necessity of having suitable Tsunami Warning Systems (TWSs) capable of protecting coastal areas from tsunami threat was considered a priority even by those countries that until then had ignored or neglected the possibility of tsunami attacks, and the idea of tackling the problem down to a community level seemed to be the only possible solution. In this frame, the IOC (Intergovernmental Oceanographic Commission) of UNESCO recommended the creation of TWSs aimed at monitoring the seas of the globe that were still not covered, namely the Indian and the Atlantic Oceans and the Mediterranean sea, and further it added the recommendation to enhance the existing TWS in the Pacific (PTWS). In 2005 Intergovernmental 
Table 1. Decision Matrix for the North-East Atlantic Ocean, proposed by the ICG/NEAMTWS in November 2010. Notice that no action is suggested when earthquakes with a depth less than $100 \mathrm{~km}$ and with $5.5<M_{\mathrm{w}} \leq 7.5$ are in the distance range between 40 and $100 \mathrm{~km}$, and for all earthquakes that are more than $100 \mathrm{~km}$ inland.

\begin{tabular}{|c|c|c|c|c|c|c|}
\hline \multicolumn{7}{|c|}{ Decision Matrix for the NE Atlantic } \\
\hline \multirow[t]{2}{*}{ Depth } & \multirow[t]{2}{*}{ Epicenter Location } & \multirow[t]{2}{*}{$M_{\mathrm{w}}$} & \multirow[t]{2}{*}{ Tsunami Potential } & \multicolumn{3}{|c|}{ Tsunami Message Type } \\
\hline & & & & Local & Regional & Basin \\
\hline \multirow{4}{*}{$<100 \mathrm{~km}$} & $\begin{array}{l}\text { Offshore or close to the } \\
\text { coast }(\leq 40 \mathrm{~km} \text { inland })\end{array}$ & $>5.5$ and $\leq 7.0$ & $\begin{array}{l}\text { Weak potential for local } \\
\text { tsunami }\end{array}$ & Advisory & Information & Information \\
\hline & & $>7.0$ and $\leq 7.5$ & $\begin{array}{l}\text { Potential for a destructive local } \\
\text { tsunami }(<100 \mathrm{~km})\end{array}$ & Watch & Advisory & Information \\
\hline & $\begin{array}{l}\text { Offshore or close to the } \\
\text { coast }(\leq 100 \mathrm{~km} \text { inland })\end{array}$ & $>7.5$ and $\leq 7.9$ & $\begin{array}{l}\text { Potential for a destructive } \\
\text { regional tsunami }(<400 \mathrm{~km})\end{array}$ & Watch & Watch & Advisory \\
\hline & & $>7.9$ & $\begin{array}{l}\text { Potential for a destructive } \\
\text { basin-wide tsunami }\end{array}$ & Watch & Watch & Watch \\
\hline$\geq 100 \mathrm{~km}$ & $\begin{array}{l}\text { Offshore or inland } \\
\leq 100 \mathrm{~km}\end{array}$ & $>5.5$ & Nil & Information & Information & Information \\
\hline
\end{tabular}

Coordination Groups (ICGs) were established within the frame of the IOC, with the mandate to foster and coordinate the implementation of Regional TWSs for the Indian Ocean (IOTWS), the Caribbean (CARIBE EWS) and the North Eastern Atlantic, the Mediterranean and Connected Seas (NEAMTWS).

Considering that most of the tsunamis are triggered by earthquakes, which is true both at global as well as at regional levels (see e.g., Dunbar, 2009, for a global catalogue; see the on-line world-ocean Historical Tsunami Database - HTDB; see also examples of regional catalogues such as Tinti et al., 2004, for Italian tsunamis and Papadopoulos et al., 2010, for tsunamis in the eastern Mediterranean), one of the main challenges of a reliable TWS is to recognise promptly if an earthquake is capable or not of triggering a tsunami and to establish the action that should be taken in case of a tsunami generation. The challenge can be managed by using a Decision Matrix (DM), which is a table that allows one to systematically identify, analyse and rate the size of the potential tsunami and to respond with appropriate actions. In fact, as soon as the preliminary earthquake parameters are available, through the matrix one can rapidly discriminate if the earthquake is potentially tsunamigenic and, then, if it can generate a local, a regional or a basin-wide tsunami and its severity. Accordingly one can decide to issue messages of the appropriate type, namely information bulletins, advisory bulletins or watch bulletins. How the procedure works is described in the Operational User Guides (OUGs) drafted by the various ICGs, such as the OUG for the Pacific ocean TWS that was approved in a revised form in August 2010 (UNESCO/IOC, 2010) and the OUG for the NEAM region.

The efficiency of a DM depends strongly on the tsunamigenic peculiarities of the area. Bearing in mind the identification and characterisation of the tsunamigenic sources in the NE Atlantic and in the Mediterranean area, the ICG of NEAMTWS developed two different DMs, respectively, for the NE Atlantic and for the Mediterranean basin, that are given in Tables 1 and 2, respectively, in the version proposed in November 2010 at the 7 th session of the ICG.

It is stressed that DMs are tools that handle only tsunamis of seismic origin. This means that at the present level of development, TWSs do not take into account tsunamis produced by other generation mechanisms, such as submarine sliding and coastal or submarine volcanic processes, that are certainly less frequent, but not less dangerous.

In this paper, we have examined the adequacy of the NEAMTWS DM for the Mediterranean for potentially tsunamigenic earthquakes that were produced by sources located in or near the seas surrounding Italy. To this purpose, we have applied the matrix to the series of the known past Italian earthquakes by making use of the most recent Italian catalogue of strong earthquakes (CPTI04, 2004), and we have tested the matrix forecast capability against the series of the known past Italian tsunamis, as reported in the most recent version of the Italian Catalogue of Tsunamis (i.e., the ITCver3 resulting from the ITC by Tinti et al., 2004 and further revisions: Graziani et al., 2006; Maramai et al., 2007), judging the performance of the matrix with regard to its ability to predict first (i) tsunami generation, and then (ii) tsunami characteristics, such as the expected range (local, regional, basin-wide) and the expected severity. Further, this retrospective application of the DM to the past Italian events has allowed us to assess the percentage of overestimations, including false alarms, as well as the percentage of underestimations, including missing alarms. 
Table 2. Decision Matrix for the Mediterranean basin, proposed by the ICG/NEAMTWS in November 2010. Notice that no action is suggested when earthquakes with a depth less than $100 \mathrm{~km}$ and with $5.5<M_{\mathrm{W}} \leq 6.5$ are in the distance range between 40 and $100 \mathrm{~km}$, and for all earthquakes that are more than $100 \mathrm{~km}$ inland.

\begin{tabular}{|c|c|c|c|c|c|c|}
\hline \multicolumn{7}{|c|}{ Decision Matrix for the Mediterranean } \\
\hline \multirow[t]{2}{*}{ Depth } & \multirow[t]{2}{*}{ Epicenter Location } & \multirow[t]{2}{*}{$M_{\mathrm{W}}$} & \multirow[t]{2}{*}{ Tsunami Potential } & \multicolumn{3}{|c|}{ Tsunami Message Type } \\
\hline & & & & Local & Regional & Basin \\
\hline \multirow{4}{*}{$<100 \mathrm{~km}$} & $\begin{array}{l}\text { Offshore or close to the } \\
\text { coast }(\leq 40 \mathrm{~km} \text { inland })\end{array}$ & $>5.5$ and $\leq 6.0$ & $\begin{array}{l}\text { Weak potential for local } \\
\text { tsunami }\end{array}$ & Advisory & Information & Information \\
\hline & & $>6.0$ and $\leq 6.5$ & $\begin{array}{l}\text { Potential for a de- } \\
\text { structive local tsunami } \\
(<100 \mathrm{~km})\end{array}$ & Watch & Advisory & Information \\
\hline & $\begin{array}{l}\text { Offshore or close to the } \\
\text { coast }(\leq 100 \mathrm{~km} \text { inland })\end{array}$ & $>6.5$ and $\leq 7.0$ & $\begin{array}{l}\text { Potential for a destruc- } \\
\text { tive regional tsunami } \\
(<400 \mathrm{~km})\end{array}$ & Watch & Watch & Advisory \\
\hline & & $>7.0$ & $\begin{array}{l}\text { Potential for a destruc- } \\
\text { tive basin-wide tsunami }\end{array}$ & Watch & Watch & Watch \\
\hline$\geq 100 \mathrm{~km}$ & $\begin{array}{l}\text { Offshore or inland } \\
\leq 100 \mathrm{~km}\end{array}$ & $>5.5$ & Nil & Information & Information & Information \\
\hline
\end{tabular}

\section{The NEAMTWS DM for the Mediterranean and the operational practice}

A DM is one of the main tools that can be used by TWSs to issue an early warning message. In the frame of the ICG/NEAMTWS a specific working group was devoted to the definition of a suitable DM for the NEAM region. The result was that two DMs were discussed and proposed in November 2010 as part of the OUG: one for the NE Atlantic and one for the Mediterranean area, the latter also holding for the Marmara sea and the Black sea. The two DMs are reported in Tables 1 and 2. Like the DM for the Pacific Ocean, also the DMs for the NEAM region are only based on earthquake parameters and, in particular on epicentre location, focal depth and magnitude $M_{\mathrm{w}}$. These are the first parameters determined by seismological centres and usually they are available in a few minutes with the present-day technology. The operational practice is that, on the occurrence of an earthquake, the preliminary source parameters (magnitude, location and depth) are calculated and entered into the DM in order to decide which kind of warning is to be launched. The first bulletin of any TWS message sequence is, therefore, issued only on the basis of earthquake data, filtered through the DM. In later steps, the warning may be updated or cancelled on the basis of updated seismic information and/or data supplied by the marine sensors network (where available) that should validate or disprove the tsunami occurrence.

In the DM, tsunamis are classified into local, regional and basin-wide events according to their expected spatial range. Following the ICG/NEAMTWS characterisation, in the Mediterranean a tsunami is considered "local" when its effects are confined to coasts that are located within $100 \mathrm{~km}$
Table 3. Spatial ranges for tsunamis occurring in the NEAM region as adopted by the ICG/NEAMTWS.

\begin{tabular}{llll}
\hline Tsunami Range & Local & Regional & Basin-wide \\
\hline NE Atlantic & $<100 \mathrm{~km}$ & $100 \mathrm{~km}$ to $1000 \mathrm{~km}$ & $>1000 \mathrm{~km}$ \\
Mediterranean & $<100 \mathrm{~km}$ & $100 \mathrm{~km}$ to $400 \mathrm{~km}$ & $>400 \mathrm{~km}$ \\
\hline
\end{tabular}

distance from the source, is called "regional" if its effects reach distances beyond $100 \mathrm{~km}$, but within $400 \mathrm{~km}$, and is said to be a "basin-wide" event if it is seen even beyond $400 \mathrm{~km}$. This type of classification holds also for the Atlantic tsunamis, but the distance limit separating regional from basin-wide cases is replaced by $1000 \mathrm{~km}$ (see Table 3 ). The spatial range identifies the geographical areas that are potentially affected by the tsunami and, therefore, the countries that should be the recipients of the warning.

Once an earthquake has occurred, there are three types of messages that can be issued following the DM and that correspond to different degrees of severity of the tsunami impact (see Table 4). The first type is the "information bulletin", that only informs of the occurrence of a major earthquake (i.e., in this context an earthquake with $M_{\mathrm{w}} \geq 5.5$ ): the shock might have triggered a tsunami that, however, is expected to be too small (wave with height less than $20 \mathrm{~cm}$ ) to cause damage in the given distance range. The second type is the "advisory bulletin", that is the second level of tsunami alert for the NEAMTWS matrix, informing that some impact can be expected on the coast, since tsunami waves can reach the height of $0.5 \mathrm{~m}$ in the near-shore, that is in harbours, in coastal channels ..., where strong currents and formation of bores can 
Table 4. Tsunami message types as defined by the ICG/NEAMTWS in the 2010 OUG.

\begin{tabular}{lll}
\hline Message Type & Tsunami Wave & Effects on the coast \\
\hline Tsunami Watch & $\begin{array}{l}\text { Tsunami wave height greater than } 0.5 \mathrm{~m} \\
\text { and/or tsunami run-up greater than } 1 \mathrm{~m}\end{array}$ & Coastal inundation \\
Tsunami Advisory & $\begin{array}{l}\text { Tsunami wave height less than } 0.5 \mathrm{~m} \\
\text { and larger than } 0.2 \mathrm{~m} \text {, and/or tsunami } \\
\text { run-up less than } 1 \mathrm{~m}\end{array}$ & $\begin{array}{l}\text { Currents, bores, recession, damage in } \\
\text { harbours, small inundation on beaches }\end{array}$ \\
Tsunami Information & & No tsunami threat \\
\hline
\end{tabular}

be observed. Moreover, run-up heights onshore can be at most $1 \mathrm{~m}$ and can determine inundation of some low-lying flat beaches. Finally, the highest level of alert is the "tsunami watch", that is issued when damage is expected to be from severe to disastrous, involving also loss of lives since waves are higher than $0.5 \mathrm{~m}$ and extended coastal inundation might occur with runup heights in excess of $1 \mathrm{~m}$.

Considering the DM for the Mediterranean shown in Table 2 , when an earthquake has $M_{\mathrm{w}}<5.5$, no bulletins are issued, since it is considered too small to produce a tsunami. On the other hand, when $M_{\mathrm{w}} \geq 5.5$, there are a number of alternatives opened. If $M_{\mathrm{w}} \geq 5.5$ and the hypocentre is very deep ( $>100 \mathrm{~km}$ ), information bulletins are issued to all countries of the TWS, though the DM foresees that no tsunami can be generated. On the other extreme, when the earthquake is submarine, has hypocentre at a depth less than $100 \mathrm{~km}$ and has a high magnitude $\left(M_{\mathrm{w}}>7.0\right)$, then a tsunami watch is issued to all countries with no distinction of spatial range, since there is the possibility that the tsunami can cause severe damage even at large distances (beyond $400 \mathrm{~km}$ ) from the origin area. In all the intermediate cases, different bulletins are issued to different countries, since distant coasts are expected to be less affected than coasts near the source. It is worth underlining that there are inland earthquakes with a special combination of magnitudes and epicentre distance from the coast for which the DM does not specify any action and, therefore, any bulletins are issued: these are the earthquakes with hypocentre less than $100 \mathrm{~km}$, and either with epicentre more than $40 \mathrm{~km}$ inland and $5.5<M_{\mathrm{W}} \leq 6.5$ or with epicentre more than $100 \mathrm{~km}$ inland and large magnitudes $\left(M_{\mathrm{W}}>6.5\right)$.

If the DM identifies the need to issue messages of "tsunami advisory" or of "tsunami watch" type, then the message is not an isolated single message, but it is the first of a sequence (see Table 5). This sequence contemplates only two messages (initial + cancellation message), if no tsunami is recorded by sea-level sensors nor is observed on the coast. On the other hand, if the tsunami is detected, a series of $N$ messages is issued, where the $N$-th message is an "all clear" message after the tsunami has passed and no more tsunami waves are expected (see Table 5). In this latter case, the intermediate bulletins (from 2 to $N-1$ ) are supplement messages including updated earthquake parameters, tide-gauge observations of tsunami waves, expected arrival times of tsunami at some specific points (called forecast points), etc. It is worth pointing out that the first bulletin of the sequence is determined only on the basis of the DM, while, in addition, all others also depend on the real observations of tsunami and, therefore, on data from the sea-level monitoring network.

\section{Method of analysis}

The adequacy of the NEAMTWS DM for the Italian area has been tested by applying it to the catalogue of the Italian strong earthquakes and by judging the suitability of the action suggested by the DM against the known characteristic of the generated tsunami: in other terms, we have examined if, by using the DM, one could have identified correctly the known historical tsunamis affecting the Italian coasts and, consequently, would have launched the appropriate alerts. To this purpose, the earthquakes that occurred since $1600 \mathrm{AD}$ up to the present and that are contained in the CPTI04 catalogue (CPTI04, 2004), were used as input to the DM and the results were compared to the descriptions of the effects of the tsunamis reported in the ITCver3, that includes 72 events, 66 of which took place after $1600 \mathrm{AD}$. The CPTI04 is a parametric catalogue of the Italian earthquakes that updates a previous catalogue (CPTI99, 1999), extends it until the end of 2002 and is the result of a long revision of the Italian strong earthquakes by a working group financed by a national project.

All the earthquake parameters that are required for the application of the DM, apart from the hypocentre depth, are available in the CPTI04, including the magnitude $M_{\mathrm{w}}$. For most of the earthquakes that are relevant for the present analysis, the value of $M_{\mathrm{w}}$ of CPTI04 is equal to the one given in CPTI99 and derives from macroseismic observations and empirical conversion laws (see also Gasperini and Ferrari, 1997). As regards the hypocentre depth, we notice that the DM only requires to discriminate between deep earthquakes (deeper than $100 \mathrm{~km}$ ) and intermediate to shallow earthquakes (less deep than $100 \mathrm{~km}$ ) and that only a few seismogenic zones have been found in Italy where deep earthquakes may occur. Subcrustal earthquakes down to $110 \mathrm{~km}$ 
Table 5. Sequence of tsunami messages as defined by the ICG/NEAMTWS in the 2010 OUG.

\begin{tabular}{lcclll}
\hline \multicolumn{5}{c}{ Sequence of Tsunami Messages } \\
\hline $\begin{array}{l}\text { Message } \\
\text { Type }\end{array}$ & $\begin{array}{l}\text { Tsunami } \\
\text { Detected }\end{array}$ & $\begin{array}{c}\text { Number } \\
\text { Messages }\end{array}$ & $\# 1$ & $\# 2 \ldots \# N-1$ & $\begin{array}{l}\text { Closing } \\
\text { Message }\end{array}$ \\
\hline Tsunami Information & & 1 & Single & - & - \\
Tsunami Advisory & No & 2 & Initial & - & Advisory Cancellation \\
Tsunami Watch & & 2 & Initial & - & Watch Cancellation \\
Tsunami Advisory & Yes & $\mathrm{N}$ & Initial & Supplement $(0,1$ or more $)$ & End of Advisory \\
Tsunami Watch & & $\mathrm{N}$ & Initial & Supplement $(0,1$ or more $)$ & End of Watch \\
\hline
\end{tabular}

have been recorded along the northern Apennine chain (see Amato et al., 1997), but since their magnitudes are less than 6.5 and their epicentres are far from the sea $(>40 \mathrm{~km})$, the application of the DM excludes that they have potential to generate tsunamis. The most important zone of very deep seismicity is the southern Tyrrhenian subduction zone where earthquakes help to identify the geometry of the Ionian slab down to the depth of $500 \mathrm{~km}$ (Selvaggi and Chiarabba, 1995; Wortel and Spakman, 2000; Monna and Dahm, 2009). This area is well defined by the instrumental seismicity and is located in the Tyrrhenian sea off western Calabria and off northern Sicily. In the present analysis, all earthquakes with epicentres falling in this area have been assumed to be deeper than $100 \mathrm{~km}$.

In total, a number of 178 earthquakes (Fig. 1) out of the 2254 post-1600 CPTI04 events passed filtering procedures based on the hypocentre depth $(\leq 100 \mathrm{~km})$ and on two combinations of the magnitude threshold and of the distance from the coast $D$ : (1) $\left(5.5<M_{\mathrm{w}} \leq 6.5\right.$ and $D \leq 40 \mathrm{~km}$; (2) $M_{\mathrm{W}}>6.5$ and $D \leq 100 \mathrm{~km}$. It is relevant to stress that going through the list of the Italian historical tsunamis one easily finds that as many as 17 tsunamis are attributed to earthquakes with magnitude smaller than the DM threshold or with no magnitude determination and 2 more tsunamis are assigned to earthquakes with magnitude in the range between 5.5 and 6.5 , but with epicentre distance larger than $40 \mathrm{~km}$ from the coast. All these cases cannot be omitted in the present analysis, since they result in missed alerts. Moreover, other not omissible cases are the non-seismic tsunamis, that is tsunamis which were triggered by volcanic activity or by landslides or for which no cause could be identified. There are 15 of such events in the Italian catalogue that occurred after $1600 \mathrm{AD}$ and that are mainly related to the volcanic activity of Vesuvius and of Stromboli. In conclusion, a total number of $212(178+17+2+15)$ cases have been taken into account in this work.

For each single event analysed, the DM assigns three outputs at local, regional and basin-wide level, hereafter called "DM actions". The three outputs, depending on the earthquakes parameters, can assume in turn three degrees of alert corresponding to the severity of the expected tsunami, as

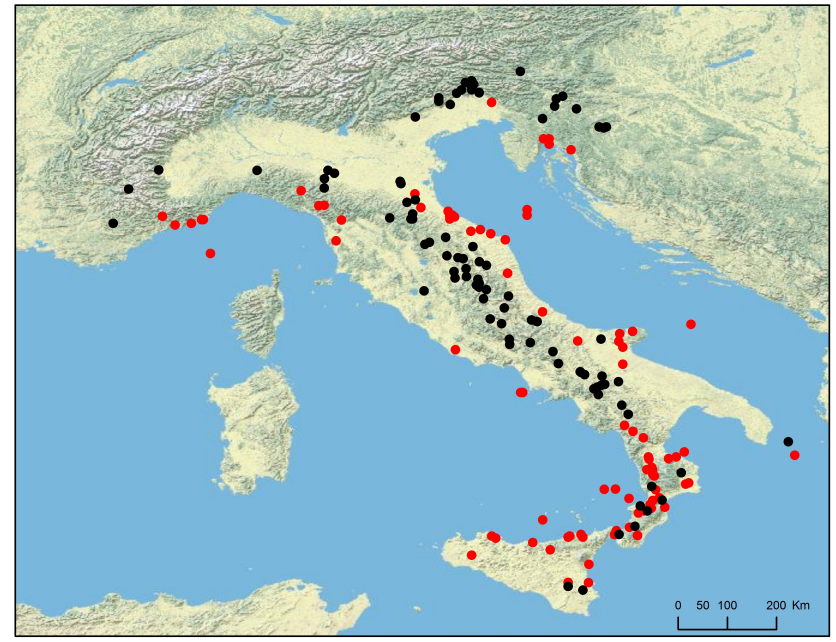

Fig. 1. Geographical distribution of the 178 CPTI04 earthquakes filtered by the DM according to the conditions: hypocentre less than $100 \mathrm{~km}$ and (1) $5.5<M_{\mathrm{W}} \leq 6.5$ and $D \leq 40 \mathrm{~km}$ (red solid circles); or (2) $M_{\mathrm{W}}>6.5$ and $D \leq 100 \mathrm{~km}$ (black solid circles). Here $D$ is the epicentral distance from the nearest coast.

suggested by the NEAMTWS guidelines, namely "information bulletin", "tsunami advisory" and "tsunami watch". For the sake of simplicity, we have associated a numerical code to each degree of alert, but we have split the category "information bulletin" into two categories: $0=$ "no tsunami info bulletin" (or simply "no tsunami"), $1=$ "tsunami info bulletin"; 2 = "tsunami advisory, 3 = "tsunami watch". More precisely, the index $0=$ "no tsunami" is assigned when the parameters of the event are such that the DM considers it as non-tsunamigenic, whereas the index $1=$ "tsunami info" is attributed when the earthquake has a potential only for a weak tsunami. Furthermore, for all the events a degree of alert at local, regional and basin-wide level has been given also according to the effects reported in the ITCver3, hereafter called in short "ITC actions", with the understanding that the real meaning is "actions consistent with the ITC reports". The criteria that has been followed to establish the degree of alert are in accordance with the NEAMTWS 
Table 6. Comparison between DM action and ITC action indexes for some events that occurred soon after $1600 \mathrm{AD}$, which is the time threshold selected in the present analysis. Before this date, both the CPTI04 and the ITCver3 are largely incomplete.

\begin{tabular}{|c|c|c|c|c|c|c|c|c|}
\hline \multirow[t]{2}{*}{ Year } & \multirow[t]{2}{*}{ Locality } & \multirow[t]{2}{*}{$M_{\mathrm{W}}$} & \multicolumn{3}{|c|}{ DM action index $i$} & \multicolumn{3}{|c|}{ ITC action index $k$} \\
\hline & & & Local & Regional & Basin-wide & Local & Regional & Basin-wide \\
\hline 1609 & Nicastro, W Calabria & 5.6 & 2 & 1 & 1 & 0 & 0 & 0 \\
\hline 1613 & Naso, NE Sicily & 5.6 & 2 & 1 & 1 & 2 & 1 & 1 \\
\hline 1624 & Mineo, E Sicily & 5.6 & 2 & 1 & 1 & 0 & 0 & 0 \\
\hline 1626 & Girifalco, E Calabria & 6.1 & 3 & 2 & 1 & 0 & 0 & 0 \\
\hline 1627 & Gargano, N Apulia & 6.7 & 3 & 3 & 2 & 3 & 3 & 2 \\
\hline
\end{tabular}

guidelines (see Table 4). Whenever "currents, bore, recession, damage in harbours, small inundation on beaches" or "wave heights less $0.5 \mathrm{~m}$ and larger than $0.20 \mathrm{~m}$ " are mentioned in the tsunami description, a "tsunami advisory" (2) has been assigned. When the description refers to "extensive coastal inundation" or "wave heights larger than $0.5 \mathrm{~m}$ ", a "tsunami watch" (3) has been attributed to the event. As regards the "tsunami info bulletin" (1), this type of message has been given to events with minor effects reported. Finally, for those earthquakes with no tsunami mentioned in the ITCver3, a "no tsunami" (0) index has been assigned. We stress that no tsunami entry in the ITCver3 does not necessarily mean that no tsunami occurred, but also that the tsunami passed unobserved because it was too small to produce damage and/or, in case it occurred with the instrumental monitoring network already in place, it was undetected due to possible deficiencies of the network and, therefore, it was unreported. In the following, it is found convenient to denote the "DM action" with the index $i$ and the "ITC action" with the index $k$. Since they are used for the various distance ranges, we distinguish them, when it is needed, as $i_{\mathrm{L}}, i_{\mathrm{R}}$ and $i_{\mathrm{BW}}$ for the respective local, regional and basin-wide scales. Likewise, the notations $k_{\mathrm{L}}, k_{\mathrm{R}}$ and $k_{\mathrm{BW}}$ will be used.

In order to compare the output of the DM ("DM actions") with the description of the tsunami effects ("ITC actions"), a table has been filled in, that contains all the indexes attributed at local, regional and basin-wide level side by side. Table 6 shows a sample of such a table displaying the results of our analysis for a few events that occurred at the beginning of the 17 th century.

The comparison between "DM action" and "ITC action" allowed us to find out those cases in which the DM is able to launch the appropriate message as well as those when the matrix fails. There are two different possibilities of failure, namely underestimation and overestimation of the event. In case of underestimation $(i<k)$, the message issued according to the DM is either inadequate (i.e., "tsunami advisory" (2) instead of "tsunami watch" (3)) or, in the worst case, non-existent (missing alarm). A missing alarm means that the DM establishes that no tsunami threat is foreseen while the earthquake triggered a tsunami, so the matrix provides wrong information misleading the end users. In case of overestimation $(i>k)$, the message issued following the DM is conservative (i.e., "tsunami watch" (3) instead of "information bulletin" (1)) providing exaggerated severity information and leading, in the worst case, to false alarm.

Table 6 shows 5 entries with earthquake epicentres inland, but close to the coast $(<40 \mathrm{~km})$. The first three (taking place in 1609, 1613 and 1624) refer to earthquakes just above the magnitude value identified by the DM as potentially tsunamigenic. As to the ITCver3 records, of the three first cases only the 1613 earthquake produced a tsunami that had some effects solely in the coastal town of Naso where flooding of the beach was reported (Incudine, 1882; Mercalli, 1883). The ITC action appropriate to such effects would be to issue an "advisory bulletin" within the range of $100 \mathrm{~km}$ from the source (including only Sicily and Calabrian coasts) (i.e., $k_{\mathrm{L}}=2$ ), and "informative bulletins" to more distant coasts (i.e., $k_{\mathrm{R}}=k_{\mathrm{BW}}=1$ ). These actions are perfectly consistent with the ones recommended by the DM $\left(i_{\mathrm{L}}=2\right.$, $\left.i_{\mathrm{R}}=i_{\mathrm{BW}}=1\right)$ and, therefore, in this case no mismatch is found. On the other hand, the cases of the 1609 earthquake that occurred in central west Calabria in the area of Nicastro and of the 1624 earthquake that occurred in the town of Mineo close to Catania, eastern Sicily, are perfectly homogeneous with the previous one as regards the DM indexes $i$ (i.e., $i_{\mathrm{L}}=2, i_{\mathrm{R}}=i_{\mathrm{BW}}=1$ ). However, since no tsunami is reported, it follows that $k_{\mathrm{L}}=k_{\mathrm{R}}=k_{\mathrm{BW}}=0$. These happen to be typical cases of overestimation, since DM imposes actions that are not really needed. The other two events shown in Table 6 concern earthquakes belonging to higher magnitude classes. The 4 April 1626 earthquake severely affected the town of Girifalco and also Catanzaro in central Calabria (Perrey, 1848; Baratta, 1901), but no mention of tsunami is made in the historical documents. This is a cause of a more severe mismatch between the DM and the ITC action, since the DM foresees the potential for a strong tsunami with some possible effects even in the intermediate distance range (i.e., beyond $100 \mathrm{~km}$ from the source). The final case is a very strong shock that occurred on the 30 July 1627 in northern Apulia, that is one of the Italian region with relevant tsunami potential (Tinti et al., 1995), with epicentre inland close to the town of San Severo, and is one of the largest earthquakes in the Italian history. There is abundant documentation on the 
Local ITC action index $k_{L}$

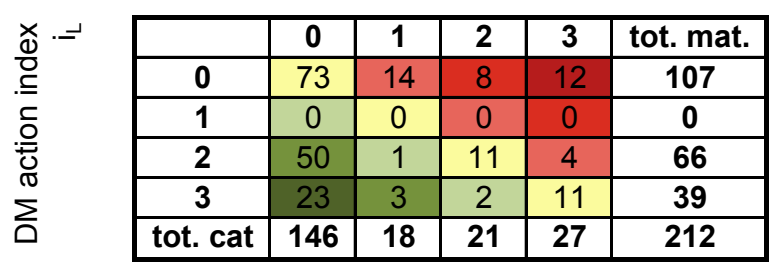

a)

Regional ITC action index $k_{R}$

\begin{tabular}{|c|c|c|c|c|c|c|}
\hline 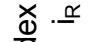 & & 0 & 1 & 2 & 3 & tot. mat. \\
\hline. & 0 & 91 & 10 & 5 & 1 & 107 \\
\hline ธ & 1 & 51 & 13 & 2 & 0 & 66 \\
\hline 0 & 2 & 12 & 0 & 5 & 0 & 17 \\
\hline & 3 & 14 & 2 & 0 & 6 & 22 \\
\hline & tot. cat & 168 & 25 & 12 & 7 & 212 \\
\hline
\end{tabular}

b)

\section{Basin-wide ITC action index $\mathrm{k}_{\mathrm{BW}}$}

\begin{tabular}{|c|c|c|c|c|c|c|}
\hline \multirow{2}{*}{\multicolumn{2}{|c|}{0}} & 0 & 1 & 2 & 3 & tot. mat \\
\hline & & 91 & 15 & 1 & 0 & 107 \\
\hline ธ & 1 & 63 & 20 & 0 & 0 & 83 \\
\hline & 2 & 14 & 2 & 3 & 0 & 19 \\
\hline & 3 & 0 & 0 & 0 & 3 & 3 \\
\hline & tot. cat & 168 & 37 & 4 & 3 & 212 \\
\hline
\end{tabular}

c)

Fig. 2. Matrices comparing DM vs. ITC actions at local (a), regional (b) and basin-wide (c) level.

shock (see Baratta, 1901; Boschi et al., 1995). Also abundant is the available information on the generated tsunami that dramatically affected the coast of the Gargano promontory and that was also revised in modern papers as regards the historical impact (Guidoboni and Tinti, 1988), the tsunami deposits (De Martini et al., 2003) and the numerical simulation of the tsunami propagation (Tinti and Piatanesi, 1996; Tinti and Armigliato, 2003). The analysis of the severity of the tsunami effects and the geographical extension of the affected area leads to ITC action indexes that are compatible with the ones imposed by the DM (see Table 6).

\section{Results of the analysis}

The results of the application of the NEAMTWS DM to the Italian area are summarised in the set of matrices of Fig. 2 where the actions prescribed by the DM are compared with the ones compatible with the ITCver 3 reports, respectively, at local (a), regional (b) and basin-wide level (c). The matrices are conceived in such a way that the indices identifying each cell $(i, k)$ coincide with the DM and ITC action indices introduced in the previous section. Each cell contain the number of events with DM action index $i$ and ITC action index $k$, with the exception of the cells in the last row $(i=4)$ and in the last column $(k=4)$ that contain partial and grand totals. In total, as many as 212 cases were analysed. In all matrices the same colour code is used for the matrix cells. Along the main diagonal, yellow cells give the number of events for which the DM action is perfectly adequate to what is required from the real tsunami occurrence, i.e., is adequate to the ITC action $(i=k)$. The underestimated cases $(i<k)$ are displayed in the upper diagonals with cells going from light to dark red representing increasing degree of failure. The dark red cells with $i=0$ and $k=3$ are the worst case since they correspond to missing alarms for large tsunami occurrences. For example, in the "Local" matrix of Fig. 2a there are 12 dark-red events that the DM evaluated as "no tsunami", while historical tsunami reports would have required the issuance of "tsunami watch" bulletins $\left(i_{\mathrm{L}}=0\right.$, $\left.k_{\mathrm{L}}=3\right)$. In an analogous way, the lower diagonals $(i>k)$ with cells going from pale to dark green represent increasing degree of overestimation, the worst case being the dark green and corresponding to false alert in case of no tsunami generation $(i=3$ and $k=0)$.

Figure 2a reveals that at local level the DM predicts correctly in 95 out of 212 cases: in particular it recognises correctly 11 "tsunami advisory" and 11 "tsunami watch". The DM is incorrect on the conservative side (green), overestimating 6 tsunami events: in 2 cases the DM prescribes "tsunami watch" instead of "tsunami advisory", whereas in 3 cases assigns "tsunami watch" instead of "tsunami info" and in 1 case a "tsunami advisory" in place of "tsunami info". Remaining on the overestimation side, one sees that the largest numbers are found in the cells $(i=2, k=0)$ and $(i=3, k=0)$ where DM forces the issuance of "tsunami advisory" bulletins (50 cases) and "tsunami watch" bulletins (23 cases) while no tsunami effects were reported. Summing up all the out-of-diagonal values of the column $k_{\mathrm{L}}=0$ one obtains the total number of false alarms that, in the present case, result to be as many as 73 . Looking at the reddish side of the table, concerning the underestimated events, one sees that slight misalignment is found in 14 cases $\left(i_{\mathrm{L}}=0\right.$ and $k_{\mathrm{L}}=1$ ) with missing "tsunami info" and 4 further cases $\left(i_{\mathrm{L}}=2\right.$ and $k_{\mathrm{L}}=3$ ) where the DM decides for "tsunami advisory" rather than "tsunami watch". Summing the cases in the first row with $i_{\mathrm{L}}=0$ and $k_{\mathrm{L}}>i_{\mathrm{L}}$, one obtains the total number of missing alarms: in total there are 34 cases of ascertained tsunami occurrences for which no action is foreseen from the application of the DM in the local range. These will be better analysed in Fig. 3 later on.

At a regional level (Fig. 2b), as many as 115 events out of 212 are correctly predicted by the DM, whereas the number of missing alarms are only 16 with a reduction by more than $50 \%$ when compared to the local-range results. As 


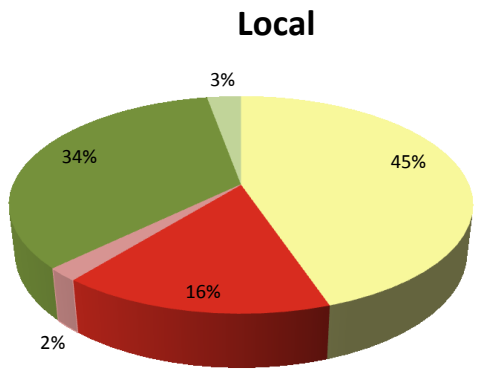

a)

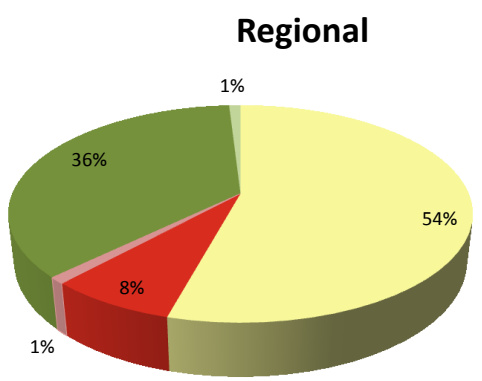

b)

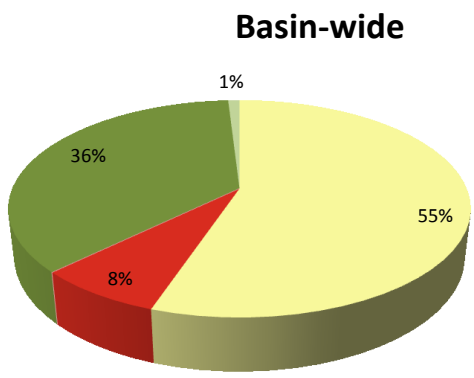

c)

Fig. 3. Performance of the DM at local (a), regional (b) and basinwide (c) level. The number of underestimated events is obtained by summing up all the out-of-diagonal values of the DM with $0<i<$ $k$, while the number of missing alarms is the sum of the values of the DM with $i=0$ and $i<k$. Analogously, the number of overestimated events is obtained by summing up all the out-of-diagonal values of the DM with $0<k<i$ and the false alarms are given by the sum of the values with $k=0$ and $i>k$.

regards false alarms, the total number (77) has slightly increased. It is important to highlight that the highest number of false alarms (51) is given by unnecessary "tsunami info" $\left(i_{\mathrm{R}}=1, k_{\mathrm{R}}=0\right)$ that indeed correspond to earthquakes offshore or close to the coast $(D<40 \mathrm{~km})$ in the magnitude range between 5.5 and 6.0 (see Table 2) and that happened to be non-tsunamigenic. The contribution of such earthquakes is pretty much the same also at local level, where the majority of false alarms (50) was given by unnecessary "tsunami advisory" (2) instead of "no tsunami" (0) (see Fig. 2a). Figure $2 \mathrm{c}$ shows the results of the DM application at basin-wide level and the numbers are very similar to those at a regional level.

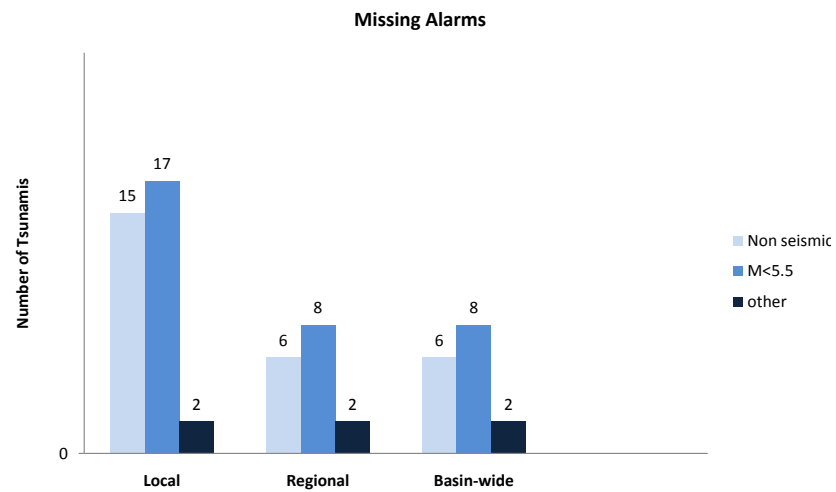

Fig. 4. Missing alarms distinct by causes and by distance range.

In order to have an alternative view of the results, the outputs given by the matrix are also presented as percentage pie-charts (see Fig. 3a, b and c) at local, regional and basinwide level. It can be noticed that, going from the local to the basin-wide level, the number of correctly predicted events mainly increases to the detriment of the number of the missing alarms and passes from $45 \%$ to $55 \%$ and is largely dominated by values in the cells $(i=0, k=0)$ (see Fig. 2a, $\mathrm{b}$ and c). It is also seen that overestimations including false alarms (37\%) greatly exceeds underestimations and missing alarms, the last one being at most $16 \%$ of the cases at the local range, and only $8 \%$ in the regional and basin-wide ranges.

The statistics of missing alarms seems acceptable, but if the analysis is limited only to the real tsunami cases (66), then figures change, since missing alarms are 34 out of 66 at a local scale and 16 out of 44 at regional and basin-wide scales. This can be justified first of all by underlining once more that the two DMs of the NEAM region given in Tables 1 and 2 were developed to deal only with tsunamis of seismic origin and, therefore, that volcanic and landslide-induced tsunamis are ruled out from the DM action and fall in the missing alarm zone $(i>0, k=0)$. Figure 4 helps clarify one more relevant reason. In the histogram, the missing alarms at the three spatial scales are represented with the specification of the partial contributions due to the different kind of tsunamigenic sources. Looking at the figure, it is evident that in addition to non-seismic sources there is also a strong contribution deriving from tsunamigenic earthquakes with a magnitude below the threshold $\left(M_{\mathrm{w}}<5.5\right)$. Not all of these small earthquakes are contained in the CPTI04 database, but they are all mentioned in the ITCver3, that provides the basic earthquake parameters of the tsunami source, including the magnitude. The diagram highlights further that the local scale is much more influenced than regional and basin-wide scales. This is partly explained by the fact that tsunamis related to landslides and/or volcanic activity (non-seismic sources) usually have a major impact on the vicinity of the source and dissipate quickly their energy since they are characterised by shorter wavelengths. 


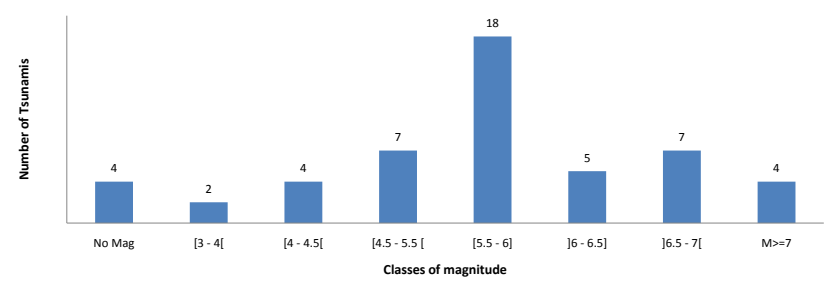

Fig. 5. Number of tsunamis (figure on the top of each column) attributed to earthquakes classified per magnitude classes. The upper classes, starting from threshold 5.5, coincide with the DM classes. A "no mag" (= no magnitude) class is added for earthquakes for which no magnitude estimate can be found in the CPTI04.

In the column "other" we have included 2 cases of ITCver3 tsunamis that were triggered by earthquakes with epicentre further than $40 \mathrm{~km}$ from the coast and, therefore, considered not tsunamigenic by the DM. According to chronology, the first one is the 2 April 1808 Valle del Pellice (close to the Italian-French border) tsunamigenic earthquake, with CPTI04 $M_{\mathrm{W}}=5.7$ and epicentral distance greater than $100 \mathrm{~km}$ from the coast, that caused a weak tsunami in Marseille (Vassalli Eandi, 1808; Tinti et al., 2004). The second one is the 9 October 1828 Valle della Staffora (north-western Italy) tsunamigenic earthquake, with estimated $M_{\mathrm{w}}=5.7$ and epicentral distance between 40 and $100 \mathrm{~km}$ from the coast, producing a tsunami in Genoa where some vessels were damaged (Baratta, 1901; Tinti et al., 2004).

Figure 5 plots the histogram of tsunamis that are associated with earthquakes categorized per magnitude classes, according to the ITCver3. The class "NO MAG" includes those tsunamis (all occurring in the pre-instrumental era) that are attributed to earthquakes whose magnitude, however, could not be estimated and cannot be found in any of the available earthquake databases. From this figure it emerges that tsunamis were observed in Italy even as a coincidence with earthquakes of very low magnitude (down to magnitude between 3-4), which in principle seems impossible. Indeed, according to the commonly used empirical relationships between magnitude and fault geometrical parameters, small earthquakes involve source areas that are too small in size and with displacements too small in magnitude to produce significant changes in the sea floor. For example, if one applies any versions of the Wells and Coppersmith (1994) relationships, one finds that magnitude 4 quakes correspond to faults with lengths in the order of $100 \mathrm{~m}$ or less, and with slip in the order of $1 \mathrm{~mm}$ or less, which, even considering the estimates uncertainty due to extrapolating the formulas well beyond the lower threshold of the magnitudes dataset on which they were derived, are values too small to induce any tsunamis. One possible solution to this contradiction or paradox is (i) that historical data are unreliable, either on the earthquake side (the real earthquake was much stronger) or on the tsunami side (no real tsunami was indeed generated); or alternatively, (ii) that historical observations are credible, but the real tsunami was not directly generated by the earthquake, but by a marine landslide triggered by the earthquake itself. Since earthquake and tsunami data were carefully scrutinized by the compilers of the two basic datasets of this study (i.e., the CPTI04 and the ITCver3), the latter hypothesis is to be preferred. Indeed invoking a submarine mass failure seems reasonable since it is known (1) that even small earthquakes can trigger landslides quite far from the source in areas prone to instability (Keefer, 2002; Delgado et al., 2011), (2) that such failures are quite hard or impossible to detect in the ocean without adequate means of high-resolution bathymetric surveying and, hence, it is not surprising that they remained unnoticed, (3) that recent programmes of extensive bathymetric investigations in the margins surrounding Italy have revealed a large number of submarine landslides previously unknown, which is suggestive of a strong susceptibility to fail for Italian margin slopes (Chiocci and Ridente, 2011). Whatever the cause of the tsunami, it is clear that DM is unable to capture these events, which will remain unalarmed.

It is known that the quality of earthquake and tsunami catalogues varies greatly over time especially in terms of completeness and the accuracy of parameters. This is the main reason we confined our analysis only to the events that occurred after $1600 \mathrm{AD}$. But one could further argue that a substantial quality discontinuity might be expected in passing from the pre-instrumental to the instrumental era and, therefore, the performance of the DM matrix for future events should be better (more fairly) estimated by restricting the analysis only to instrumental events. Since it is hard to single out all the events whose relevant parameters were determined only on the basis of instrumental records, we have divided our database into two subsets according to a simple chronological criterion, namely events that occurred in the time period 1600-1899 and events occurred in the following period 1900-present day, under the reasonable assumption that the data of the latter subset are higher quality than the former one. Though it is an imperfect wording, we will refer to them as pre-instrumental and instrumental data. In this way, the total set of 212 events was split into 140 pre-instrumental and 72 instrumental events. After applying our analysis separately to these subsets, we found that the results are quite similar for the two classes and, consequently, that they are also similar to the ones obtained before in considering the whole dataset, as shown in Fig. 6a, b and c.

Finally, the results of our analysis are plotted in chronological order for all the 212 examined cases in Fig. 7 where, for each event, one finds the comparison between the "DM action" (blue diamond) and the "ITC actions" (red framed square) at local, regional and basin-wide level. The error bar (black horizontal line) represents the degree of under/overestimation and, in case of correctly predicted event, the symbols overlap. In the figure, we have also highlighted 5 events that can be considered interesting examples of the way 

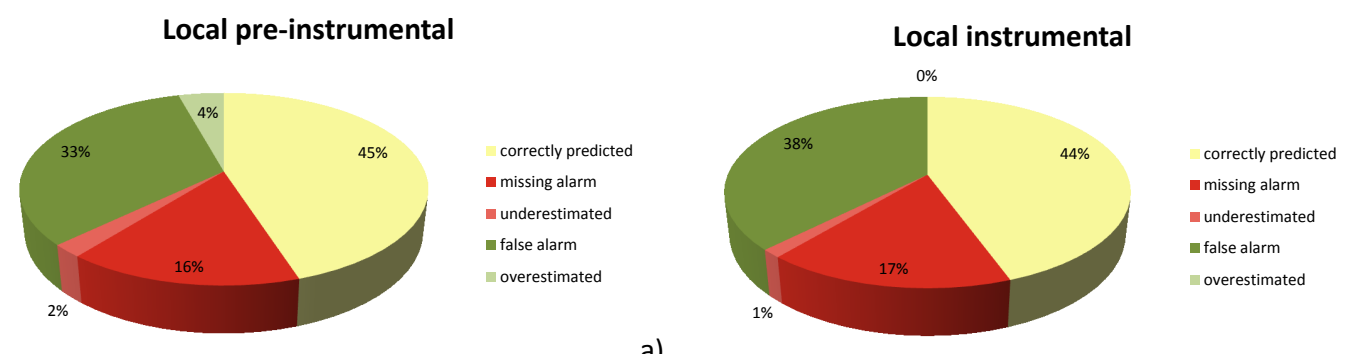

a)

Regional pre-instrumental
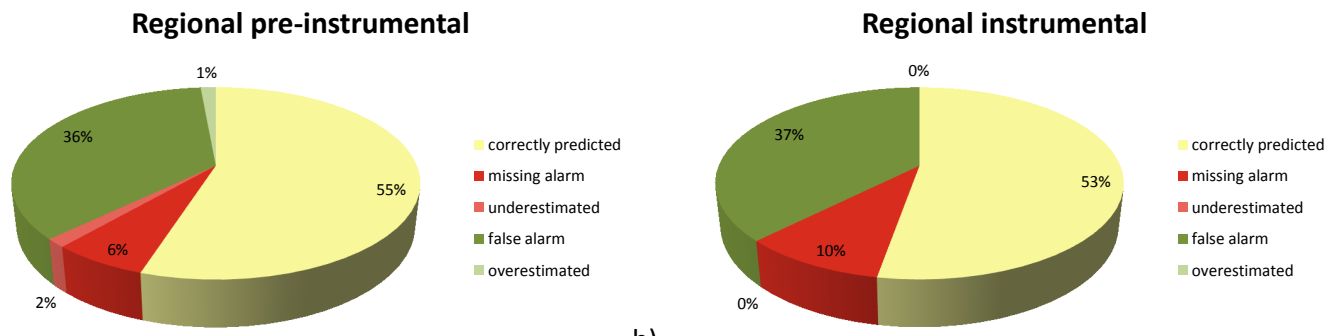

b)
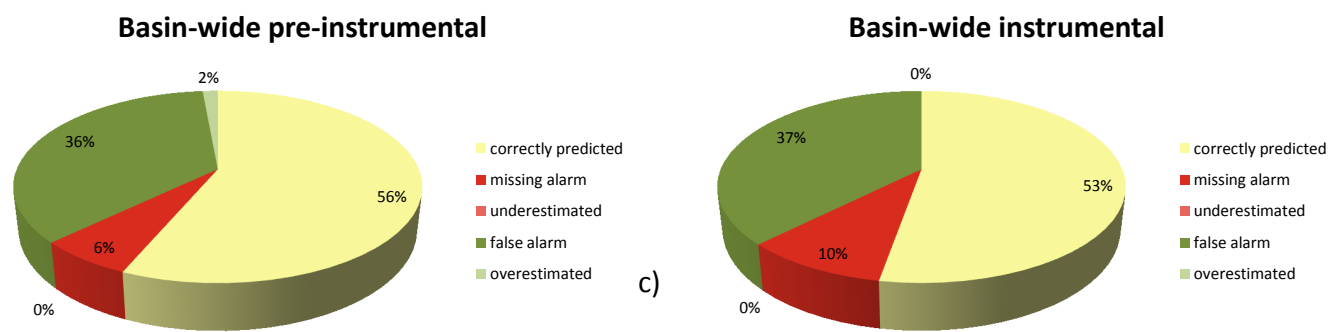

Fig. 6. Performances of the DM at local (a), regional (b) and basin-wide (c) level: comparison between pre-instrumental (1600-1899) and instrumental (1900 to present day) data. Frequencies of the various categories do not vary much from one subset to the other and are also similar to the one of the global dataset shown in Fig. 3.

the DM works: They are included in white boxes with magnified symbols and are representative of underestimation, overestimation or good estimate.

The 11 January 1693 eastern Sicily tsunami and the 28 December 1908 Messina Straits tsunami are examples of cases in which the DM action is correct at all spatial levels (symbols overlap). They were induced by two of the largest earthquakes in the seismic history of Italy with respective CPTI04 magnitude $M_{\mathrm{w}}=7.4$ and $M_{\mathrm{w}}=7.2$. Both tsunamis have been the object of intense research in recent years and hypotheses have been advanced that their source was not exclusively the earthquake, but also some landslides in the Hyblean-Malta escarpment, and in the Messina Straits or on the Mt. Etna offshore complex, respectively (Tinti et al., 1999, 2001; Gutscher et al., 2006; Favalli et al., 2009; Billi et al., 2010; Argnani et al., 2012). Such debate has no relevance in this context, since, whatever the real cause, there is no doubt that the DM predictions are adequate. The 6 February 1783 Calabrian tsunami, that was triggered by a coastal landslide induced by a $M_{\mathrm{w}}=5.9$ earthquake, is a typical example of underestimation. At local level the DM issues a "tsunami advisory", while the tsunami had catastrophic effects locally, causing more than 1500 casualties (Tinti et al., 2004; Graziani et al., 2006). In this case, a "tsunami watch" bulletin would have been the right message to launch. At regional and basin-wide level the DM predicts correctly an "information bulletin" $\left(i_{\mathrm{R}}=i_{\mathrm{BW}}=1\right)$ which is appropriate compared to the observed tsunami effects. The $30 \mathrm{De}-$ cember 2002 Stromboli tsunami is an example of missing alarm. In this case the DM fails to launch any alarm because the tsunami was triggered by landslides detached during a paroxystic eruptive crisis of the volcano. Unfortunately the tsunami produced severe damage locally and its effects were observed in a basin-wide area embracing the southern Tyrrhenian sea (Maramai et al., 2005; Tinti et al., 2008). Finally, an example of false alarm is the 1978 Gulf of Patti (northern Sicily) earthquake. This is an event with a magnitude greater than 6.0 and, therefore, the matrix assigns a local "tsunami watch" bulletin, a regional "tsunami advisory" bulletin and a basin-wide "information bulletin". Actually, no tsunami effects were reported and, most probably, the tsunami was not triggered because the earthquake was a strike-slip quake that occurred in a transcurrent faults system (Barbano et al., 1979). 


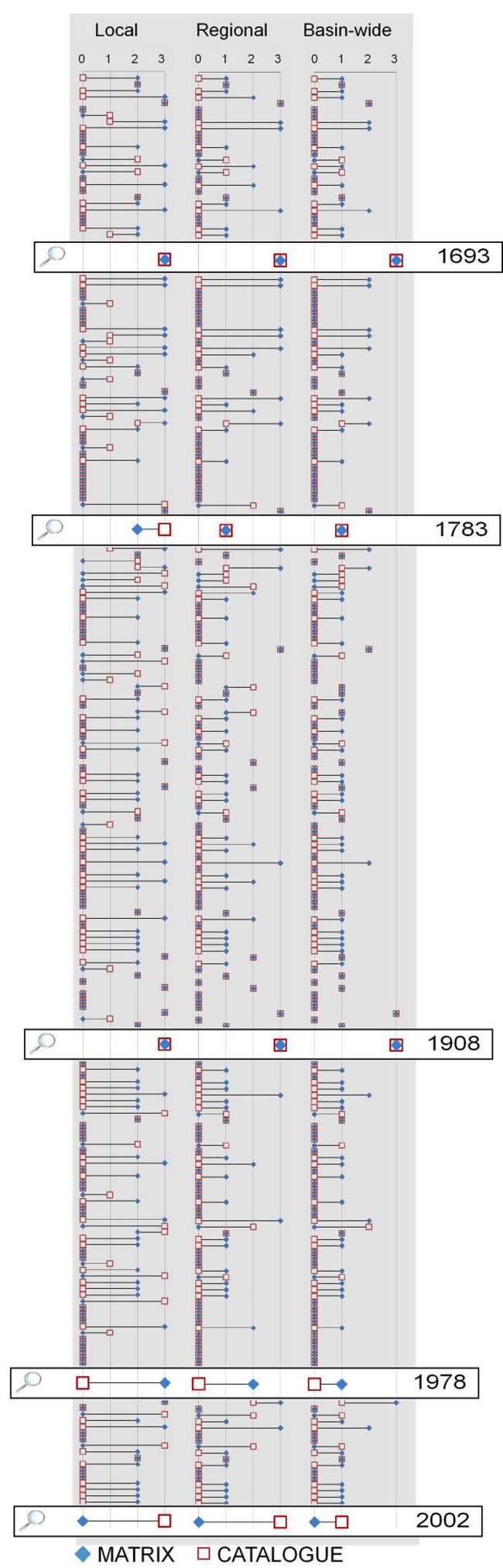

Fig. 7. Graph comparing DM and ITC actions in chronological order for all the 212 cases analysed. The longer the segment of a case, the larger the discrepancy.

\section{Conclusions}

The ITCver 3 is a reliable and detailed collection of information, both parametrical and descriptive, on Italian tsunamis that provides a good picture of the effects produced by historical and recent tsunamis and that gives the possibility in evaluating the severity as well as the propagation extent of the events. The idea of this work was to verify the applicability of the NEAMTWS DM to the Italian context and to compare the output with the real tsunami data. For this purpose, the DM was applied to the Italian earthquakes occurred since $1600 \mathrm{AD}$ to present days, with the scope to check if the messages prescribed by the DM correspond to the degree of severity of the real tsunami effects reported in the catalogue descriptions. The comparison between theoretical and real data allow to quantify the number of false and missing alarms as well as the correctly predicted events.

We have introduced four categories of DM actions and the corresponding categories of ITC actions, denoted by the respective indices $i$ and $k$, ranging from 0 to 3 , with index increasing with the severity of the tsunami. The main conclusion is that the DM actions in the various distance scales are correct (i.e., $i=k$ ) only in a range between $45-55 \%$ of cases, that overestimations $(i>k)$ are $37 \%$ and underestimations $(i<k)$ vary from $8-18 \%$ of the total. The most numerous cases fall in the category $(i=k=0)$ : these are earthquakes with $M_{\mathrm{w}} \geq 5.5$ that DM correctly recognises as non-tsunamigenic since they are too deep or too far from the coast. In these cases the DM prescribes the issuance of an information bulletin to all countries of the Mediterranean basin, which would be the only bulletin issued.

The statistics on the complete dataset given above, and also displayed in Fig. 3, is worth further analysis that can be made by considering the matrices of Fig. 2. Let us consider separately the cases of no tsunami occurrences $(k=0)$ and tsunami occurrences $(k>0)$. On limiting to data in the first column of the matrices, one sees that in the local range (Fig. 2a) $50 \%$ (73 events) of the earthquakes were correctly identified as non-tsunamigenic and $50 \%$ were incorrectly predicted as tsunamigenic (false alarm), and that in both other ranges (Fig. 2b and c) the correct predictions increase to $54 \%$.

If one restricts the performance analysis to tsunami cases $(k>0)$, one sees that all 66 ITCver3 tsunamis are local (Fig. 2a) and that as many as 44 are also regional (Fig. 2b) and basin-wide (Fig. 2c). Out of the 66 tsunamis at local level, only 22 are estimated correctly, 6 are overestimated and 38 underestimated, which is far from being satisfactory. At regional level, figures improve slightly since the right estimates increase to 24 (out of 44 ), the overestimates are only 2 , while the underestimates are 18. And at the basin-wide level, we have the best performance with 26 correct estimates, 2 overestimates and 16 underestimates. It is clear that in case of tsunami occurrences underestimates seem to be more frequent than overestimates, that is in contrast with the 
general statistics over the entire dataset of 212 cases. However, if one excludes from these computations all cases of tsunamis of non-seismic origin (see Fig. 4), that are not covered by the DM, then underestimations reduce to 25 at local level, and only to 12 and 10, respectively, at regional and basin-wide level. This reduces the unbalance between underestimations and overestimations, but still leaves predominance to underestimates.

It is further interesting to observe that, when the analysis was repeated separately on data before 1900 (preinstrumental) and after 1900 (instrumental), the frequencies of correct estimates, overestimations, underestimations (see Fig. 6a, b and c) were found to be quite stable with respect to the total set.

The main conclusion that can be drawn from our analysis is (1) that the predictive power of the DM is quite low at all distance ranges, (2) that it is worse at the local scale than at regional and basin-wide scales, (3) that in case of a tsunami occurrence one might expect a tendency to under-predict the severity of the effects and expect good predictions only in about $33 \%(41 \%)$ of cases locally and in about $54 \%(61 \%)$ of cases at higher ranges (frequencies in parenthesis exclude non-seismic tsunamis from calculations). The consequence of this unfavourable statistic is that the DM reveals to be a rather unreliable tool, which poses two problems: (1) how to use it profitably in the practice of an operative TWS; (2) to search for possible improvements.

One possible solution to the first problem is that in the operative procedures of a TWS, the DM is used only to take the first decision as soon as an earthquake occurs. This means that in case of failure of the DM (in case of inappropriate action), the TWS might have the opportunity to correct it at a later stage. Indeed, after issuing the first bulletin, a TWS could use the following bulletins in the sequence described in Table 5 to correct the content of the first one, as more data (more accurate seismic data and especially tidegauge observations) arrive. In this way the number of underand overestimations, but above all of false alarms and, most importantly, of missing alarms can be drastically reduced. However, this possible correction may regard more the regional and basin-wide bulletins, since they are directed at countries that are more distant from the source and, therefore, are reached by the tsunami later. Unfortunately corrections to bulletins directed to local coasts could reach the involved countries too late, that is after the main tsunami impact has taken place.

A solution to the second problem is quite complex and is outside the scope of this paper, but some considerations can be made here. There are two possible strategies to search for improvements. One way is to keep the concept of the DM and of its general scheme, based on classes of magnitude, of hypocentre depth and of distance from the coast, and to perform a sensitivity analysis to search for the class boundaries that provide the best performance. Following this approach, we mention that we have changed the value of the epicentre distance from the coast from 40 up to $100 \mathrm{~km}$. Increasing this parameter has the consequence that DM takes earthquakes that are more distant from the coast as tsunamigenic, although most of them are not: the result was the noticeable increase of the number of false alarms and a small reduction of the number of missing alarms. Decreasing the magnitude threshold would have the same effect, but much more amplified since a large number of non-tsunamigenic earthquakes would enter in the analysis (about 800 if the threshold is lowered to $M=5$, and as many as 2000 if it is lowered to $M=4.5$ ) which leads to a large increase of false alarms. But increasing such magnitude threshold would have an even worse effect. For instance, if we assume $M=6.0$ as the threshold, we know from Fig. 5 that as many as 18 tsunamigenic earthquakes will be discarded, which means that the number of missing alarms would increase significantly. From the above gross considerations, it appears that readjusting the DM by changing the parameter classes is not expected to produce important improvement in the DM performance.

A second way, but still within the frame of the same strategy, is to increment the number of parameters by taking into account, for instance, the focal mechanism of the earthquake. It is known that normal and thrust fault earthquake have much more tsunami potential than strike-slip earthquakes since they induce more substantial vertical displacement of the sea floor (being equal all the rest, namely seismic moment, focal depth, fault size, etc.). Addition of focal parameters in the DM would, therefore, better characterise the source and is reasonable to expect better results from such an improved matrix. Testing of this enhanced matrix against historical catalogues, however, is not possible since focal mechanism of historical earthquakes generally is not known and is quite hard to ascertain. It can only be speculatively deduced from geological and tectonic considerations once the epicentre of the earthquake, and consequently the corresponding seismogenic zone, is known. Indeed the CPTI04 does not contain any information on fault geometry and slip direction. But the major objection to the use of focal mechanism as additional set of information for the DM is that even with modern technology assessing focal mechanism is a process much slower than locating the earthquake and computing its magnitude. Usually focal mechanism solutions are available only after 20-30 min from the earthquake occurrence, if not later and, therefore, cannot be used for issuing the first bulletins for Italian tsunamis, that have much lower leading time.

A totally alternative strategy is to discard the concept of the DM itself and to base prediction on scenarios that can be "triggered" by the same parameters that are the input of the DM, i.e., earthquake magnitude, epicentral coordinates and depth. A large number of scenarios is pre-calculated by means of suitable tsunami numerical models and archived, and one or some combination of these is selected and used for the forecast and to issue the alerts. This strategy was initially introduced by the JMA (Japan Meteorological Agency) 
that is responsible for the Japanese TWS and has been recently adopted in other countries such as Indonesia where a TWS has been set up after the 2004 Indian Ocean tsunami mainly in cooperation with Germany in the frame of the joint German-Indonesia project GITEWS (Rudloff et al., 2009; Lauterjung at al., 2010) and Australia where a TWS is operational since 2009 (Allen and Greenslade, 2010). The process of decision in this case is based on observations and on tsunami model results, but in certain circumstances, especially for non-distant tsunamis, it might be a much more complicated task for the TWS operator and might require specific systems of decision support (see Steinmetz, 2010, for the GITEWS system) based on sophisticated information and communication technology tools, that are a real challenge for today and future research (e.g., see the efforts made within the ongoing European project TRIDEC for the development of a general purpose platform for early warning, including tsunami applications - http://www.tridec-online. $\mathrm{eu} /$ ). Decision support systems (DSS) will likely substitute the DM within TWS, although, for the sake of the truth, it is worth remarking that their performance has still to be proven in a context like the Mediterranean and Italy, in particular, and this will be a subject of future work.

A further consideration concerns the fact that, whatever the system used (DM or DSS) there will always be uncertainty in the system prediction that is mainly due to "scarcity" of data that can be collected in the short time needed to launch an effective, i.e., a timely, alarm. Since uncertainty is unavoidable, this means that the recipient of the alarm must be aware of such uncertainty and take subjective decisions selecting what to do according to his own needs and propensities. Some can decide to under-react by taking the risk of greater losses and some can decide to over-react by taking the risk and the cost of exaggerated countermeasures. In this respect, bulletins should be seen as a tool to provide the best possible information and recommendations, not prescriptive but suggesting responses. This calls for the direct and full involvement of local communities and of the local civil protection authorities in the process of early warning since they have the fundamental role of evaluating the information supplied by the warning system and of applying any further mitigation action.

Eventually it is worth stressing that the DM, but also the today's existing scenario-based DSS, have been designed only for tsunamis of seismic origin. If one takes into account that a significant number of tsunamis are associated to volcanoes, it is evident that this is a remarkable limitation for the DM performance. In fact, the Mediterranean area, especially the Italian peninsula, is characterised by an intense volcanic activity that sometimes in the past has been the triggering source of tsunamis. Similarly, the DM does not take into account tsunamis generated by landslides, which is an additional limiting factor for the DM performance. In this context, the importance of testing and deploying observational systems capable of detecting the landslide itself, and the quick determination of those parameters that are relevant for tsunami generation is a priority and a specific DM for the landslide generation mechanism should be developed, considering the landslide parameters (i.e., landslide volume, thickness, front extension, acceleration, etc.). Anyhow, at present the knowledge of the tsunami generation process by underwater body motion is not yet completely understood and is still a subject of intense research.

Acknowledgements. The work of this paper was inspired and started in the frame of the project TRANSFER (FP6 EU Project no. 037058; http://www.transferproject.eu/). The work has been completed thanks to the project TRIDEC (FP7 EU project no. 258723; http://www.tridec-online.eu/) and is a contribution to the development of the Decision Matrix concept and application in the ICG/NEAMTWS.

The authors are sincerely indebted to the referees V. Gusiakov and D. Greenslade for their valuable suggestions.

Edited by: E. Pelinovsky

Reviewed by: V. K. Gusiakov and D. Greenslade

\section{References}

Allen, S. C. R. and Greenslade, D. J. M.: Model-based tsunami warnings derived from observed impacts, Nat. Hazards Earth Syst. Sci., 10, 2631-2642, doi:10.5194/nhess-10-2631-2010, 2010.

Amato, A., Chiarabba, C., and Selvaggi, G.: Crustal and deep seismicity in Italy (30 years after), Annali di Geofisica, 40, 981-993, 1997.

Argnani, A., Armigliato, A., Pagnoni, G., Zaniboni, F., Tinti, S. and Bonazzi, C.: Active tectonics along the submarine slope of south-eastern Sicily and the January 11, 1693 earthquake and tsunami, Nat. Hazards Earth Syst. Sci., submitted, 2012.

Baratta, M.: I terremoti d'Italia. Saggio di storia, geografia e bibliografia sismica italiana con 136 sismocartogrammi, Forni Editore, Torino, 950 pp., 1901 (in Italian).

Barbano, M. S., Bottari, A., Carveni, P., Cosentino, M., Federico, B., Fonte, G., Lo Giudice, E., Lombardo, G., and Patanè, G.: Macroseismic study of the Gulf of Patti earthquake in the geostructural frame of North-Eastern Sicily, Boll. Soc. Geol. It., 98, 155-174, 1979.

Billi, A., Minelli, L., Orecchio, B., and Presti, D.: Constraints to the cause of three historical tsunamis $(1908,1783$, and 1693) in the Messina Straits region, Sicily, Southern Italy, Seism. Res. Lett., 81, 907-915, 2010.

Boschi, E., Ferrari, G., Gasperini, P., Guidoboni, E., Smriglio, G., and Valensise, G.: Catalogo dei forti terremoti in Italia dal 461 a.C. al 1980, ING-SGA, Bologna with CD-ROM, 973 pp., 1995 (in Italian).

Chiocci, F. L. and Ridente, D.: Regional-scale seafloor mapping and geohazard assessment, The experience from the Italian project MaGIC (Marine Geohazards along the Italian Coasts), Mar. Geophys. Res., 32, 13-23, 2011. 
CPTI04: Gruppo di lavoro CPTI, Catalogo Parametrico dei Terremoti Italiani, Versione 2004 (CPTI04), INGV, Bologna, available at: http://emidius.mi.ingv.it/CPTI04 (last access: December 2011), 2004 (in Italian).

CPTI99: Gruppo di Lavoro CPTI, 1999 - ING, GNDT, SGA, SSN, Bologna, 1999, 92 pp., 1999.

Delgado, J., Garrido, J., Lopez-Casado, C., Martino, S., and Pelaez, J. A.: On far field occurrence of seismically induced landslides, Eng. Geol., 123, 204-213, 2011.

De Martini, P. M., Burrato, P., Pantosti, D., Maramai, A., Graziani, L., and Abramson, H.: Identification of tsunami deposits and liquefaction features in the Gargano area (Italy): paleoseismological implication, Ann. Geophys., 46, 883-902, 2003, http://www.ann-geophys.net/46/883/2003/.

Dunbar, P.: Integrated Tsunami Data for Better Hazard Assessments, Eos Trans. AGU, 90, 189, doi:10.1029/2009EO220001, 2009.

Favalli, M., Boschi, E., Mazzarini, F., and Pareschi, M. T.: Seismic and landslide source of the 1908 Straits of Messina tsunami (Sicily, Italy), Geophys. Res. Lett., 36, L16304, doi:10.1029/2009GL039135, 2009.

Gasperini, P. and Ferrari, G.: Stima dei parametri sintetici: nuove elaborazioni, in: Catalogo dei Forti Terremoti in Italia dal 461 a.C. al 1990, edited by: Boschi, E., Ferrari, G., Gasperini, P., Guidoboni, E., Smriglio, G., and Valensise, G., ING e SGA, Bologna, 56-64, 1997 (in Italian).

Graziani, L., Maramai, A., and Tinti, S.: A revision of the 17831784 Calabrian (southern Italy) tsunamis, Nat. Hazards Earth Syst. Sci., 6, 1053-1060, doi:10.5194/nhess-6-1053-2006, 2006.

Guidoboni, E. and Tinti, S.: A review of the historical 1627 tsunami in the Southern Adriatic, Sci. Tsunami Hazards, 6, 11-16, 1988.

Gutscher, M.-A., Roger, J., Baptista, M.-A., Miranda, J. M., and Tinti, S.: The source of the 1693 Catania earthquake and tsunami (Southern Italy): New evidence from tsunami modeling of a locked subduction fault plane, Geophys. Res. Lett., 33, L0830933, doi:10.1029/2005GL025442, 2006.

HTDB: on-line Historical Tsunami Data Base, maintained by the Tsunami Laboratory, Institute of Computational Mathematics and Mathematical Geophysics, Novosibirsk, Russia, available at: http://tsun.sscc.ru/nh/tsun_descr.html, last access: December 2011

Incudine, C.: Naso Illustrata, Storia e documenti di una civiltà municipale, Napoli, 369 pp., 1882 (in Italian).

Lauterjung, J., Münch, U., and Rudloff, A.: The challenge of installing a tsunami early warning system in the vicinity of the Sunda Arc, Indonesia, Nat. Hazards Earth Syst. Sci., 10, 641646, doi:10.5194/nhess-10-641-2010, 2010.

Keefer, D. K.: Investigating landslides caused by earthquakes - A historical review, Surv. Geophys., 23, 473-510, 2002.

Maramai, A., Graziani, L., Alessio, G., Burrato, P., Colini, L., Cucci, L., Nappi, R., Nardi, A., and Vilardo G.: Near- and farfield survey report of the 30 December 2002 Stromboli (Southern Italy) tsunami, Mar. Geol., 215, 93-106, 2005.

Maramai, A., Graziani, L., and Tinti, S.: Investigation on tsunami effects in the central Adriatic Sea during the last century - a contribution, Nat. Hazards Earth Syst. Sci., 7, 15-19, doi:10.5194/nhess-7-15-2007, 2007.

Mercalli, G.: Vulcani e fenomeni vulcanici in Italia: Geologia d'Italia, Parte 3, Milano, 374 pp., 1883 (in Italian).
Monna, S. and Dahm, T.: Three-dimensional $\mathrm{P}$ wave attenuation and velocity upper mantle tomography of the southern Apennines-Calabrian Arc subduction zone, J. Geophys. Res., 114, B06304, doi:10.1029/2008JB005677, 2009.

Papadopoulos, G. A., Daskalaki, E., Fokaefs, A., and Giraleas, N.: Tsunami hazard in the Eastern Mediterranean Sea: strong earthquakes and tsunamis in the West Hellenic Arc and trench system, J. Earthq. Tsun., 4, 145-179, 2010.

Perrey, A.: Mémoire sur les tremblements de terre de la Peninsule Italique, in: Mém. couron. et mém. des sav. étrang. Acad. R. Belgique, Brussels, tome XXII, 1848.

Rudloff, A., Lauterjung, J., Münch, U., and Tinti, S.: Preface "The GITEWS Project (German-Indonesian Tsunami Early Warning System)", Nat. Hazards Earth Syst. Sci., 9, 1381-1382, doi:10.5194/nhess-9-1381-2009, 2009.

Selvaggi, G. and Chiarabba, C.: Seismicity and P-wave velocity image of the Southern Tyrrhenian subduction zone, Geophys. J. Int., 121, 818-826, 1995.

Steinmetz, T., Raape, U., Teßmann, S., Strobl, C., Friedemann, M., Kukofka, T., Riedlinger, T., Mikusch, E., and Dech, S.: Tsunami early warning and decision support, Nat. Hazards Earth Syst. Sci., 10, 1839-1850, doi:10.5194/nhess-10-1839-2010, 2010.

Tinti, S. and Armigliato, A.: The use of scenarios to evaluate tsunami impact in South Italy, Mar. Geol., 199, 221-243, 2003.

Tinti, S. and Piatanesi, A.: Numerical simulations of the tsunami induced by the 1627 earthquake affecting Gargano, southern Italy, J. Geodynam., 21, 141-160, 1996.

Tinti, S., Maramai, A., and Favali, P.: The Gargano Promontory: an important seismogenic-tsunamigenic area, Mar. Geol., 122, 227-241, 1995.

Tinti, S., Armigliato, A., Bortolucci, E., and Piatanesi, A.: Identification of the source fault of the 1908 Messina earthquake through tsunami modelling. Is it a possible task?, Phys. Chem. Earth, Part B, 24, 417-421, 1999.

Tinti, S., Armigliato, A., and Bortolucci, E.: Contribution of tsunami data analysis to constrain the seismic source: the case of the 1693 eastern Sicily earthquake, J. Seismol., 5, 41-61, 2001.

Tinti, S., Maramai, A., and Graziani, L.: The new catalogue of the Italian tsunamis, Nat. Hazards, 33, 439-465, 2004.

Tinti, S., Armigliato, A., Manucci, A., Pagnoni, G., Tonini, R., Zaniboni, F., Maramai, A., and Graziani, L.: The double landslide-induced tsunami - in: Learning from Stromboli and its 2002-03 eruptive crisis, American Geophysical Union - Geophysical monograph, edited by: Calvari, S., Inguaggiato, S., Puglisi, G., Ripepe, M., and Rosi, M., Vol. 182, 404 pp., The Stromboli Volcano: An Integrated Study of the 20022003 Eruption (12.25.09) Geophys. Monogr. Ser., Vol. 182, 399 pp., hardbound, 2008, ISBN 978-0-87590-447-4, AGU Code GM1824474, 2008.

TRANSFER project: available at: http://www.transferproject.eu, last access: December 2011.

UNESCO/IOC: Operational Users Guide for the Pacific Tsunami Warning and Mitigation System (PTWS) revised August 2010, IOC Technical Series No. 87, 166 pp., 2010.

Vassalli Eandi, A. M.: Sopra il tremuoto che da sette mesi scuote le valli del Pelice, del Chisone e del Po, Memorie di Matematica e Fisica della Società Italiana delle Scienze, 14, 238-281, 1808 (in Italian). 
Wells, D. L. and Coppersmith, K. J.: New Empirical Relationships among Magnitude, Rupture Length, Rupture Width, Rupture Area, and Surface Displacement, Bull. Seism. Soc. Am., 84, 974-1002, 1994.
Wortel, M. J. R. and Spakman, W.: Geophysics - Subduction and slab detachment in the Mediterranean-Carpathian region, Science, 290, 1910-1917, 2000. 